Supporting Information for

\title{
Superconductivity at $4.8 \mathrm{~K}$ and Violation of Pauli Limit in $\mathrm{La}_{2} \mathrm{IRu}_{2}$ Comprising $\mathrm{Ru}$ Honeycomb Layer
}

Hajime Ishikawa*t, Ulrich Wedig ${ }^{+}$, Jürgen Nuss ${ }^{+}$, Reinhard K. Kremer ${ }^{+}$, Robert Dinnebier ${ }^{t}$, Marian Blankenhorn $^{\dagger}$, Mohammad Pakdaman $^{\dagger}$, Yosuke Matsumoto ${ }^{\dagger}$, Tomohiro Takayama ${ }^{\dagger+}$, Kentaro Kitagawa $^{\S}$, Hidenori Takagi ${ }^{\dagger \xi}$

†nstitute for Functional Matter and Quantum technologies, Universität Stuttgart, 70569 Stuttgart, Germany

${ }^{\ddagger}$ Max Planck Institute for Solid State Research, Heisenbergstraße 1, 70569 Stuttgart, Germany

${ }^{\S}$ Department of Physics, The University of Tokyo, 7-3-1 Hongo, Bunkyo-ku, Tokyo 113-0033, Japan

*hishikawa@issp.u-tokyo.ac.jp 
(a)
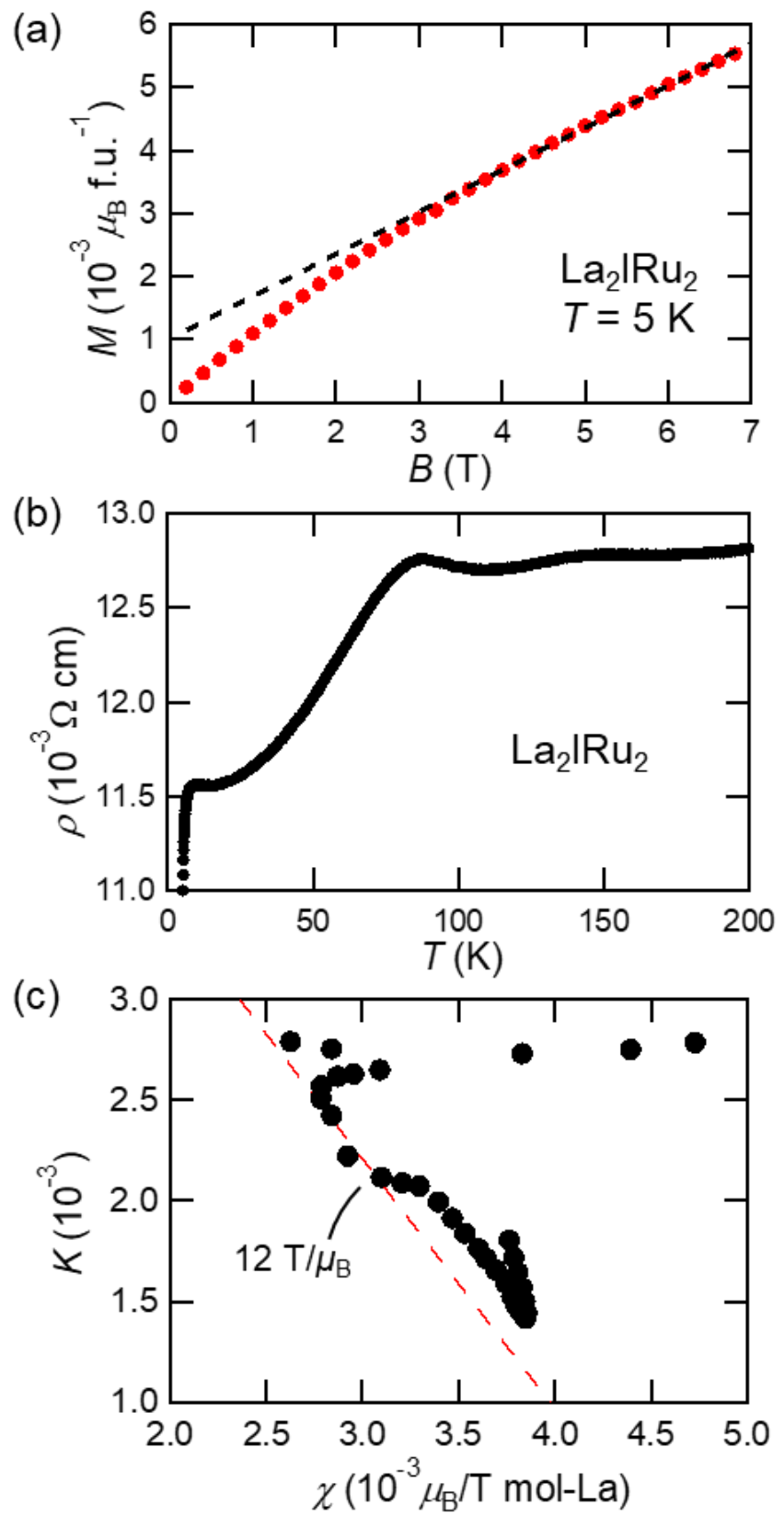

Figure S1. (a) Magnetization curve of $\mathrm{La}_{2} \mathrm{IRu}_{2}$ at $5 \mathrm{~K}$. The dashed line is the linear fit of the data above $5 \mathrm{~T}$, of which intercept with the vertical axis estimates the amount of impurity spin of $0.001 \mu_{\mathrm{B}} /$ f.u.. (b) Temperature dependence of the resistivity of the pellet of $\mathrm{La}_{2} \mathrm{IRu}_{2}$, which is made from the same powder sample shown in the main text. The phase transitions at 140 and $85 \mathrm{~K}$ and the superconductivity are observed, while the upturn below $20 \mathrm{~K}$ is not reproduced, indicating the upturn below $20 \mathrm{~K}$ in the data in the main text is extrinsic likely caused by the degradation of electrode. (c) $K-\chi$ plot and linear fit. A fit between 40 and $80 \mathrm{~K}$ below $T_{\mathrm{a} 2}$ gives $12 \mathrm{~T} / \mu_{\mathrm{B}}$. The data below $30 \mathrm{~K}$ cannot be used for the fit due to the free-spin-like component in $\chi$. 


\section{Details of WIEN2k calculations}

Table S1. Computational parameters

\begin{tabular}{|c|c|c|c|}
\hline & $\begin{array}{c}\text { Semi-core and Valence } \\
\text { Shells }\end{array}$ & $\begin{array}{c}\text { Atomic radii } \\
(\mathrm{RMT})\end{array}$ & Basis \\
\hline $\mathrm{La}$ & $5 s^{2} 5 p^{6} 5 d^{1} 6 s^{2}$ & 3.50 a.u. & $\begin{array}{c}\text { APW }+ \text { lo } \\
\text { LO for } 1=0,1,2\end{array}$ \\
\hline $\mathrm{I}$ & $4 d^{10} 5 s^{2} 5 p^{5}$ & 3.00 a.u. & $\begin{array}{c}\text { APW }+ \text { lo } \\
\text { LO for } 1=0,2\end{array}$ \\
\hline $\mathrm{Ru}$ & $4 s^{2} 4 p^{6} 4 d^{7} 5 s^{1}$ & 2.33 a.u. & $\begin{array}{c}\text { APW }+ \text { lo } \\
\text { LO for } 1=0,1\end{array}$ \\
\hline
\end{tabular}

- The choice of smaller atomic radii (e.g. default values in the WIEN2k) leads to larger contributions of the interstitial space to the DOS.

- lnsmax $=6$ (max. $l$-value used in the computation of the non-muffin-tin matrix elements.)

- $k$-mesh: $50 \times 50 \times 10$. $k$-points with no shift is applied. In total, $1350 k$-points in the irreducible part of the Brillouin zone were considered.
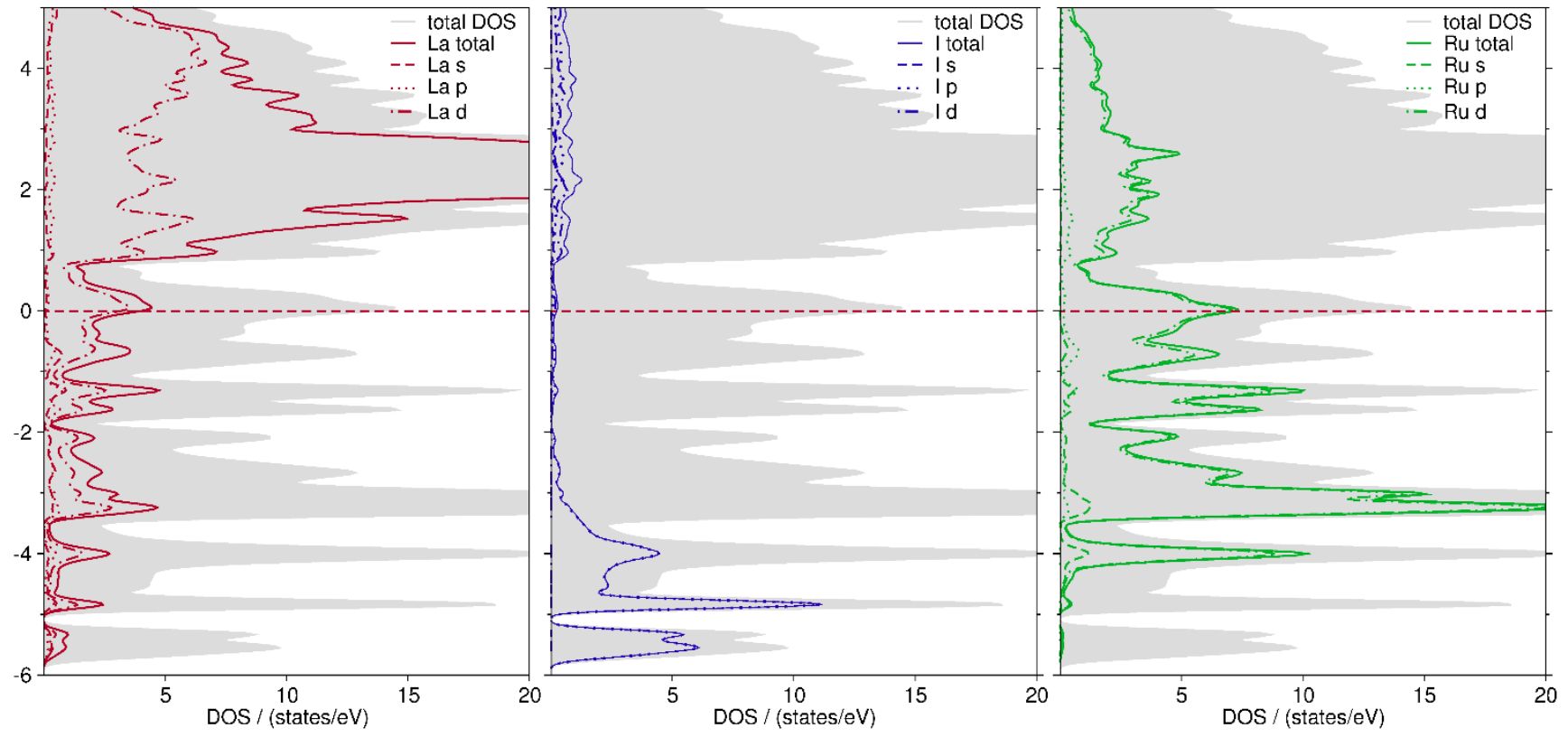

Figure S2. Angular momentum projected $\mathrm{DOS}$ of $\mathrm{La}, \mathrm{I}$ and $\mathrm{Ru}$ atoms in $\mathrm{La}_{2} \mathrm{IRu}_{2}$. These projections are obtained from the same calculation as the band structure and DOS in Fig. 5 in the main text. 

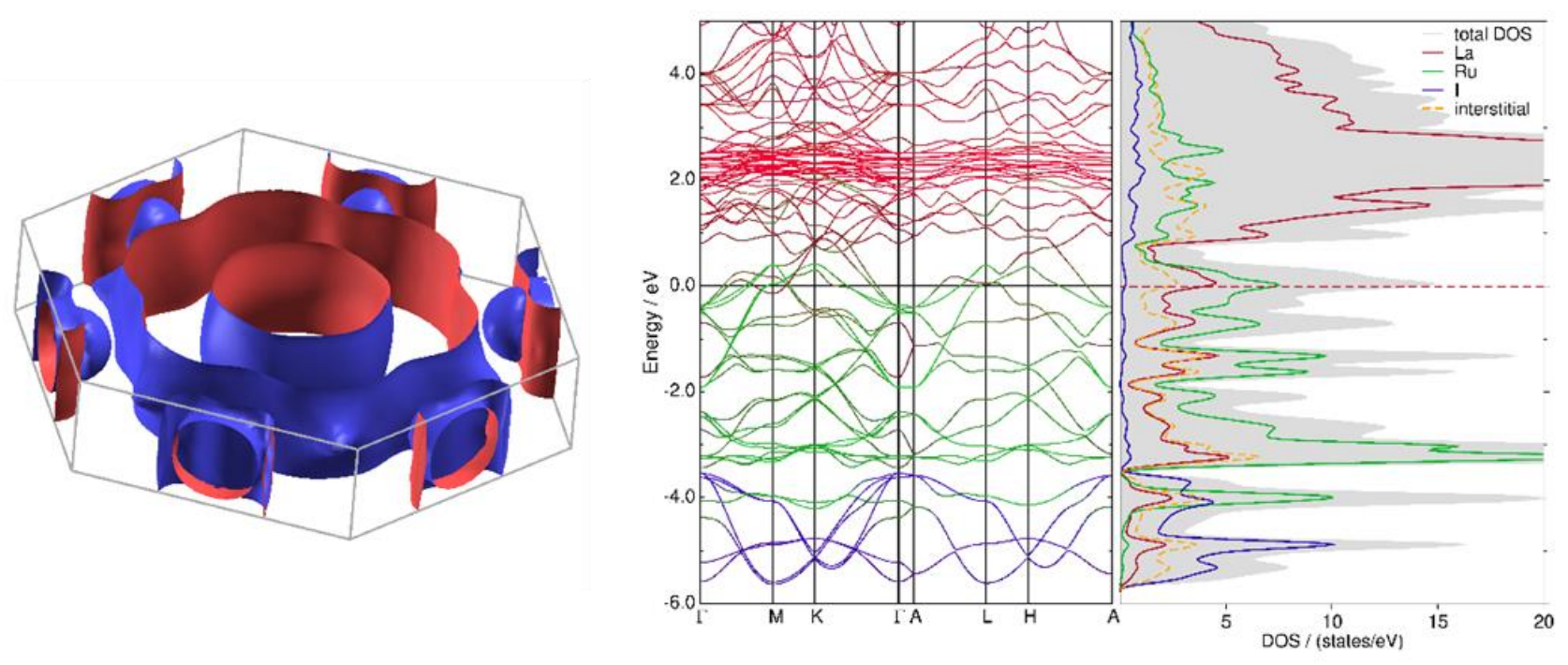

Figure S3. Fermi surface (left) and band structure and DOS (right) of $\mathrm{La}_{2} \mathrm{IRu}_{2}$ obtained from the scalar relativistic calculation. These results can be compared to the corresponding results in Fig. 5 in the main text, where spin-orbit coupling was considered.

Table S2. Structural parameters in the optimized structure

\begin{tabular}{|c|c|c|}
\hline & Experimental $(70 \mathrm{~K})$ & Optimized \\
\hline$a(\AA)$ & 4.288 & 4.264 \\
\hline$c(\AA)$ & 17.777 & 17.573 \\
\hline$z$ of La & 0.1085 & 0.1061 \\
\hline$z$ of $\mathrm{Ru}$ & 0.0041 & 0.0002 \\
\hline
\end{tabular}

- Scalar relativistic calculation with one-step optimization for the lattice constants $(a$ and $c)$ and atomic coordinates ( $z$ of La and $\mathrm{Ru}$ ) was performed with atomic radii of 3.0 a.u. for the La, 2.8 a.u. for the I, and 2.2 a.u. for the Ru atoms. 

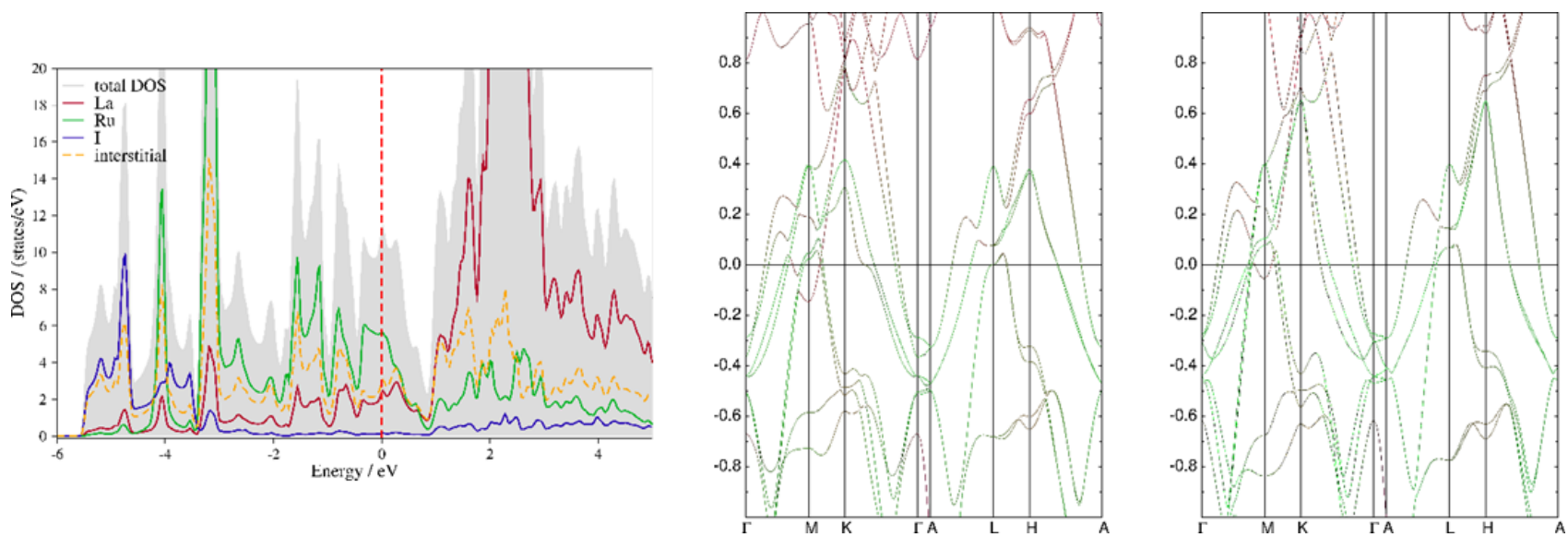

Figure S4. DOS for the optimized structure from scalar relativistic calculation (left). Band structure near the Fermi level for the experimental structure at $70 \mathrm{~K}$ (middle) and for the optimized structure (right) including spin-orbit coupling.
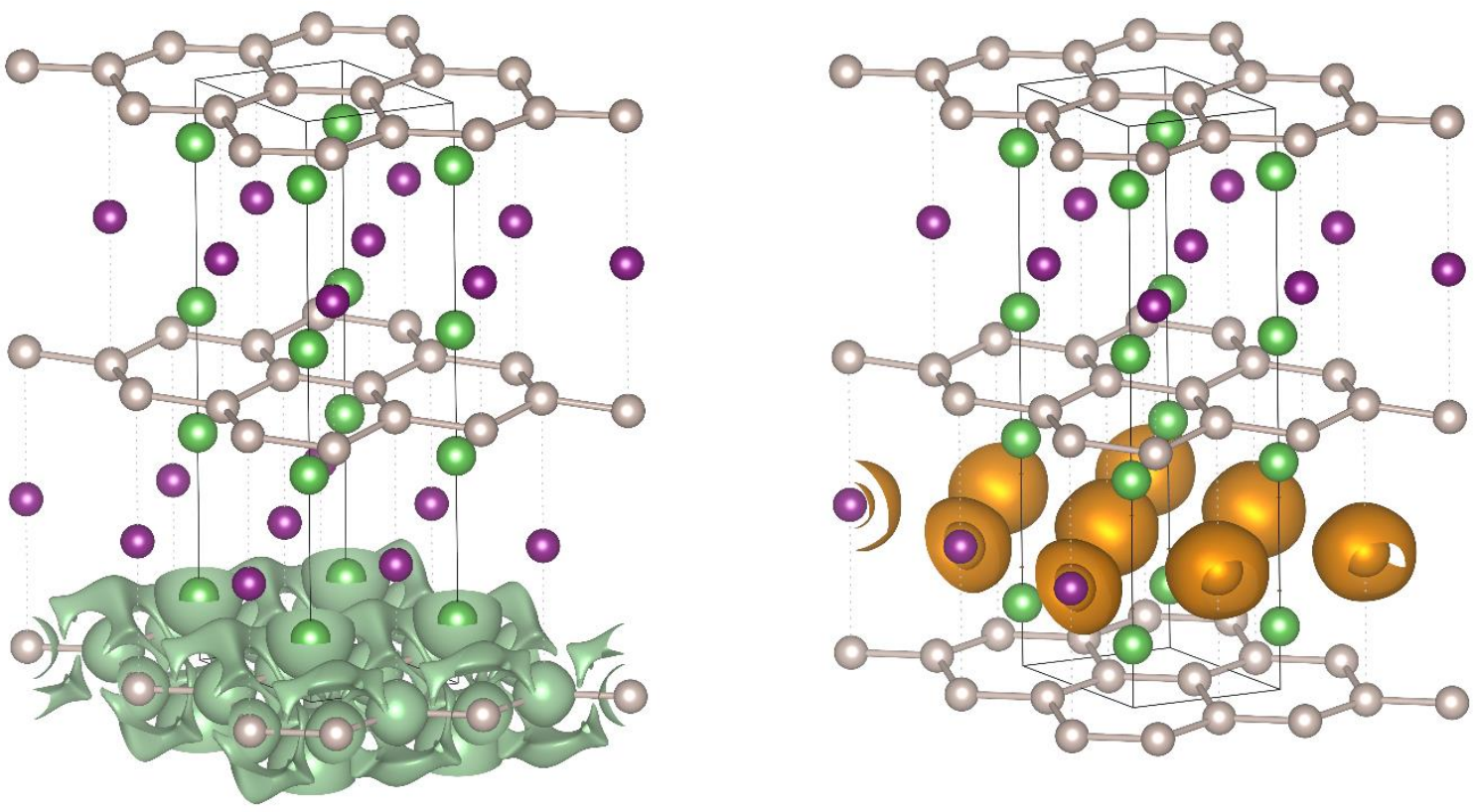

Figure S5: Domains of the electron localization function (ELF) within the $\mathrm{Ru}^{-}$honeycomb layer at $\eta=$ 0.38 (left) and within the $\mathrm{I}^{-}$layer at $\eta=0.75$ (right).

- The electron Localization function $\mathrm{ELF}^{1,2}$ of $\mathrm{La}_{2} \mathrm{IRu}_{2}$ was computed with the CRYSTAL17 $7^{3}$ code, using local Gaussian basis functions and scalar relativistic pseudopotentials. Spin-orbit coupling was not considered. 
Computational parameter for the ELF calculations

\begin{tabular}{|c|c|c|c|c|c|c|}
\hline & \multicolumn{2}{|l|}{ La } & \multicolumn{2}{|l|}{ I } & \multicolumn{2}{|l|}{$\mathbf{R u}$} \\
\hline $\begin{array}{l}\text { Pseudopotential } \\
\text { core } \\
\text { valence } \\
\text { Reference }\end{array}$ & \multicolumn{2}{|c|}{$\begin{array}{l}{[\mathrm{Kr}] 4 d^{10}} \\
5 s^{2} 5 p^{6} 5 d^{1} 6 s^{2} \\
(4)\end{array}$} & \multicolumn{2}{|l|}{$\begin{array}{l}{[\mathrm{Kr}] 4 \mathrm{~d}^{10}} \\
5 \mathrm{~s}^{2} 5 \mathrm{p}^{5} \\
(5)\end{array}$} & \multicolumn{2}{|c|}{$\begin{array}{l}{[\mathrm{Ar}] 3 \mathrm{~d}^{10}} \\
4 \mathrm{~s}^{2} 4 \mathrm{p}^{6} 4 \mathrm{~d}^{6} 5 \mathrm{~s}^{2} \\
(6)\end{array}$} \\
\hline Basis set & exponent & coefficient & exponent & coefficient & exponent & coefficient \\
\hline s-shell & $\begin{array}{l}5.0873990 \\
4.2709780 \\
1.9154580 \\
\\
0.5255960 \\
0.2634740\end{array}$ & $\begin{array}{l}-0.4172430 \\
0.8860100 \\
-1.4197520 \\
1.0 \\
1.0\end{array}$ & $\begin{array}{l}2.1227650 \\
1.7704810 \\
0.3130840\end{array}$ & $\begin{array}{l}1.1040280 \\
-1.5353260 \\
0.751603\end{array}$ & $\begin{array}{l}7.9365700 \\
5.9842450 \\
4.8822200 \\
\\
1.1446240 \\
0.5230170 \\
0.25\end{array}$ & $\begin{array}{l}-1.1196656 \\
1.4453293 \\
0.6261653 \\
1.0 \\
1.0 \\
1.0\end{array}$ \\
\hline p-shell & $\begin{array}{l}3.0251610 \\
2.3820950 \\
0.5844260 \\
0.2603600\end{array}$ & $\begin{array}{l}0.5381960 \\
-0.9816400 \\
1.2395900 \\
1.0\end{array}$ & $\begin{array}{l}2.4328870 \\
2.1372490 \\
0.3145460\end{array}$ & $\begin{array}{l}0.4422320 \\
-0.5838090 \\
0.6266060\end{array}$ & $\begin{array}{l}3.7546090 \\
2.9165710 \\
1.0486750 \\
0.5073200 \\
0.2673980\end{array}$ & $\begin{array}{l}-4.7226565 \\
4.9909084 \\
0.7285467 \\
0.3039043 \\
1.0\end{array}$ \\
\hline sp-shell & 0.10 & $\begin{array}{ll}1.0 & 1.0\end{array}$ & $\begin{array}{l}0.18 \\
0.09\end{array}$ & $\begin{array}{ll}1.0 & 1.0 \\
1.0 & 1.0\end{array}$ & 0.12 & $\begin{array}{ll}1.0 & 1.0\end{array}$ \\
\hline d-shell & $\begin{array}{l}1.5768240 \\
0.5923900 \\
0.2495000 \\
0.1065130\end{array}$ & $\begin{array}{l}-0.0969440 \\
0.4074660 \\
0.7043630 \\
1.0\end{array}$ & 0.186597 & 1.0 & $\begin{array}{l}6.0099130 \\
2.1042800 \\
0.9215000 \\
0.3885980 \\
0.2 \\
0.1\end{array}$ & $\begin{array}{l}-0.0327160 \\
0.2657392 \\
0.4812398 \\
0.4099778 \\
1.0 \\
1.0\end{array}$ \\
\hline
\end{tabular}

Functional: Range separated hybrid functional HSEsol ${ }^{7}$.

Shrink and tolerance parameters used in the CRYSTAL17 input:

SHRINK 1224

TOLINTEG 1616161632

TOLPSEUD 16

TOLDEE 8

BIPOLAR 128128 


\section{REFERENCES}

(1) Becke, A. D.; Edgecombe, K. E.; A simple measure of electron localization in atomic and molecular systems. J. Chem. Phys. 1990, 92, 5397-5403.

(2) Savin, A.; Becke, A. D.; Flad, J.; Nesper, R.; Preuss, H.; von Schnering, H. G.; A new look at electron localization. Angew. Chem. Int. Ed. Engl. 1991, 30, 409-412.

(3) Dovesi, R.; Erba, A.; Orlando, R.; Zicovich-Wilson, C. M.; Civalleri, B.; Maschio, L.; Rérat, M.; Cassassa, S.; Baima, J.; Salustro, S.; Kirtman, B.; Quantum-mechanical condensed matter simulations with CRYSTAL. WIREs Comput. Mol. Sci, 2018, e1360.

(4) Dolg, M.; Stoll, H.; Savin, A.; Preuss, H.; Energy-adjusted pseudopotentials for the rare earth elements. Theor. Chim. Acta 1989, 75, 173-194.

(5) Bergner, A.; Dolg, M.; Küchle, W.; Stoll, H.; Preuss, H.; Ab initio energy-adjusted pseudopotentials for elements of groups 13-17. Mol. Phys. 1993, 80, 1431-1441.

(6) Andrae, D.; Haeussermann, U.; Dolg, M.; Stoll, H.; Preuss, H.; Energy-adjusted ab initio pseudopotentials for the second and third row transition elements. Theor. Chim. Acta, 1990, 77, 123-141.

(7) Schimka, L.; Harl J.; Kresse G.; Improved hybrid functional for solids: The HSEsol functional. J. Chem. Phys., 2011, 134(2), 024116. 